\title{
Dual-Layer Spectral Detector CT in Comparison with FDG-PET/CT for the Assessment of Lymphoma Activity
}

\section{Dual-Layer Spektraldetektor-CT im Vergleich mit FDG-PET/CT zur Beurteilung von Lymphomaktivität}

Authors

Kim Gehling ${ }^{10}$, Theresa Mokry1, 2, Thuy Duong Do', Frederik Lars Giesel ${ }^{3,4}$, Sascha Dietrich ${ }^{5}$, Uwe Haberkorn ${ }^{3,6,7}$, Hans-Ulrich Kauczor ${ }^{1,7}$, Tim Frederik Weber ${ }^{1}$

Affiliations

1 Department of Diagnostic and Interventional Radiology, University Hospital Heidelberg, Germany

2 German Cancer Research Center (DKFZ) Division of Radiology, Heidelberg, Germany

3 Department of Nuclear Medicine, University Hospital Heidelberg, Germany

4 Department of Nuclear Medicine, University Hospital of Düsseldorf, Dusseldorf, Germany

5 Clinic for Haematology, Oncology and Rheumatology, University Hospital Heidelberg, Germany

6 Clinical Cooperation Unit Nuclear Medicine, German Cancer Research Center (DKFZ), Heidelberg, Germany

7 Translational Lung Research Center Heidelberg (TLRC), German Center for Lung Research (DZL), Heidelberg, Germany

\section{Key words}

lymphoma, iodine, PET-CT, fluorine, radioactive, CT

received 12.09.2021

accepted 23.12.2021

published online 24.02 .2022

Bibliography

Fortschr Röntgenstr 2022; 194: 747-754

DOI 10.1055/a-1735-3477

ISSN 1438-9029

(C) 2022. Thieme. All rights reserved.

Georg Thieme Verlag KG, Rüdigerstraße 14,

70469 Stuttgart, Germany

\section{Correspondence}

Kim Gehling

Department of Diagnostic and Interventional Radiology, University Hospital Heidelberg, INF 420, 69120 Heidelberg, Germany

Tel.: +49/6221/5632853

kim@gehling.de

\section{ABSTRACT}

Purpose In patients with malignant lymphoma, disease activity is recommended to be assessed by FDG-PET/CT and the Deauville five-point scale (5-PS). The purpose of this study was to explore the potential of iodine concentration measured in contrast-enhanced dual-layer spectral detector CT (SDCT) as an alternative surrogate parameter for lymphoma disease activity by investigating its correlation with maximum standardized uptake values (SUV $\left.{ }_{\max }\right)$ and 5-PS.

Materials and Methods 25 patients were retrospectively analyzed. Contrast-enhanced SDCT and FDG-PET/CT were performed in the same treatment interval within at most 3 months. CT attenuation values (AV), absolute iodine concentrations (aIC), and normalized iodine concentrations (nIC) of lymphoma lesions were correlated with SUV max $_{\text {ming }}$ Spearman's rank correlation coefficient. The performance of aIC and nIC to detect lymphoma activity (defined as 5-PS >3) was determined using ROC curves.

Results 60 lesions were analyzed, and 31 lesions were considered active. AV, aIC, and nIC all correlated significantly with SUV $_{\max }$. The strongest correlation (Spearman $\rho=0.71$; $\mathrm{p}<0.001$ ) and highest area under the ROC curve (AUROC) for detecting lymphoma activity were observed for nIC normalized to inferior vena cava enhancement $(A U R O C=0.866)$. The latter provided sensitivity, specificity, and diagnostic accuracy of $87 \%, 75 \%$, and $80 \%$, respectively, at a threshold of 0.20. ROC analysis for AV (AUROC $=0.834)$ and aIC (AUR$O C=0.853$ ) yielded similar results.

Conclusion In malignant lymphomas, there is a significant correlation between metabolic activity as assessed by FDGPET/CT and iodine concentration as assessed by SDCT. lodine concentration shows promising diagnostic performance for detecting lymphoma activity and may represent a potential imaging biomarker.

Key Points:

- Iodine concentration correlates significantly with SUV $\mathrm{max}_{\max }$ in lymphoma patients

- lodine concentration may represent a potential imaging biomarker for detecting lymphoma activity

- Normalization of iodine concentration improves diagnostic performance of iodine concentration

\section{Citation Format}

- Gehling K, Mokry T, Do TD et al. Dual-Layer Spectral Detector $\mathrm{CT}$ in Comparison with FDG-PET/CT for the Assessment of 
Lymphoma Activity. Fortschr Röntgenstr 2022; 194: 747754

\section{ZUSAMMENFASSUNG}

Ziel Zur Bestimmung der Krankheitsaktivität maligner Lymphome werden das FDG-PET/CT und die Deauville 5-PunkteSkala (5-PS) empfohlen. Als potenzieller CT-basierter Biomarker für Krankheitsaktivität kann die Jodkonzentration in Lymphomläsionen mit der Dual-Layer Spektraldetektor-CT (SDCT) quantifiziert werden. Ziel dieser Studie war, die Jodkonzentration mit den SUV-Werten $\left(S_{\text {max }}\right)$ zu korrelieren und die diagnostische Wertigkeit der Jodkonzentration mit der 5-PS als Referenzstandard zu bestimmen.

Material und Methoden 25 Lymphompatienten wurden retrospektiv analysiert. SDCTs in der portalvenösen Phase und FDG-PET/CTs wurden innerhalb von maximal 3 Monaten ohne zwischenzeitlichen Therapiewechsel durchgeführt. Der Zusammenhang zwischen CT-Dichtewerten, absoluten Jodkonzentrationen (alC) sowie normalisierten Jodkonzentrationen (nIC) und SUV $_{\max }$ wurden mittels Spearman-Rangkorrelationskoeffizienten untersucht. Die Vorhersagekraft von alC und nIC zur Beurteilung der Lymphomaktivität (5-PS>3) wurde durch Receiver Operating Characteristics (ROC)-Kurven geprüft.
Ergebnisse Insgesamt wurden 60 Läsionen analysiert und 31 Läsionen gemäß 5-PS als aktiv gewertet. CT-Dichtewerte,

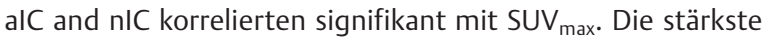
Korrelation (Spearman $\rho=0.71 ; p<0.001$ ) und der höchste Wert für die Fläche unter der ROC-Kurve (AUROC) zur Detektion von Lymphomaktivität wurde für nIC normalisiert auf die Vena cava inferior beobachtet $(A U R O C=0.866)$. Hierfür ergaben sich eine Sensitivität von $87 \%$, eine Spezifität von $75 \%$ sowie eine Genauigkeit von $80 \%$ bei einem Schwellenwert von 0.20. ROC-Analysen für die Dichtewerte $($ AUROC $=0.834)$ und aIC (AUROC $=0.853)$ zeigten vergleichbare Ergebnisse.

Schlussfolgerung Die mittels SDCT ermittelte Jodkonzentration korreliert signifikant mit der mittels FDG-PET/CT ermittelten metabolischen Aktivität maligner Lymphome. Die Jodkonzentration zeigt vielversprechende diagnostische Vorhersagekraft zur Detektion von Lymphomaktivität.

\section{Kernaussagen:}

- Die Jodkonzentration maligner Lymphome korreliert signifikant mit SUV-Werten

- Die Jodkonzentration stellt einen potenziellen Biomarker für die Detektion von Lymphomaktivität dar

- Die Normalisierung der Jodkonzentration verbessert die diagnostische Vorhersagekraft

\section{Introduction}

In patients with malignant lymphoma, 2-deoxy-2-[ $\left.{ }^{18} \mathrm{~F}\right]$ fluoroD-glucose (FDG)-positron emission tomography (PET)/X-ray computed tomography $(\mathrm{CT})$ has initiated substantial changes in both the concept and practice of lymphoma staging [1] and now plays a central role in staging and treatment response assessment [2]. FDG-PET/CT was first incorporated into response assessment criteria by the international working group in 2007 because of its superior diagnostic value compared to CT alone [3]. In order to identify active lymphoma, metabolic activity is measured and scored according to the Deauville 5-point scale (5-PS) as described by Barrington et al. and Follows et. al, respectively $[2,4]$. The integral CT part is used for attenuation correction and aids with the anatomical correlation if abnormal FDG-uptake is detected. For PET/CT, diagnostic contrast-enhanced CT (ce-CT) may be performed although low-dose CT without contrast is more commonly used [5]. Ce-CT in conjunction with FDG-PET/ $\mathrm{CT}$ is recommended to be performed at least at baseline to identify any findings to determine specific follow-up procedures [2].

For staging purposes in solid tumors, CT usually serves as the modality of choice using iodinated contrast agents for better contrast [6]. The introduction of dual-energy technology in CT has advanced tissue discrimination considerably. This method is based on obtaining attenuation measurements at two separate X-ray photon energy spectra at once. The acquired spectral data can then be used to reconstruct numerous image types, including virtual non-contrast images, virtual monoenergetic images and effective atomic numbers. Current state-of-the-art dual-layer spectral detector CT (SDCT) utilizes a single $x$-ray tube and two layers of detectors. Thus, low-energy and high-energy photons are absorbed simultaneously, providing spectral data with every scan. Spectral data can be further utilized to reconstruct iodine maps comprised of pixels representing iodine concentration in $\mathrm{mg} / \mathrm{ml}$ [7]. Clinical studies have already shown the benefit of iodine concentration as a marker of lesion vascularization for different solid tumors. For instance, recent studies found iodine concentration to be a useful indicator for evaluating tumor angiogenesis and prognosis in lung cancer [8] and hepatocellular carcinoma [9].

The purpose of this study was to explore the potential of iodine concentration as an alternative surrogate parameter for lymphoma disease activity by investigating its correlation with maximum standardized uptake value (SUV $\max$ ) and 5-PS. Assuming the iodine distribution in the tissue correlates with the local blood volume and vascular density [10], we expected to find higher iodine concentrations for higher Deauville scores.

\section{Materials and Methods}

\section{Study Design}

This was a retrospective exploratory single-center study approved by the local ethics committee with a waiver of informed consent (S-348/2019). The study period was from January 2018 to June 2019. Inclusion criteria were: (1) adult patient diagnosed with malignant lymphoma; (2) availability of both FDG-PET/CT and contrast-enhanced SDCT of the chest, abdomen, and pelvis, performed within 3 months without interim lymphoma treatment; 
(3) presence of lymphoma lesions with measurable FDG-uptake (Deauville score $\geq 2$ ).

The primary outcome measures were $\mathrm{CT}$ attenuation values (AV) as well as absolute (aIC) and normalized (nIC) iodine concentrations of lymphoma lesions as assessed by SDCT in patients diagnosed with typically FDG-avid malignant lymphoma. Iodine concentrations were correlated on a per lesion basis with established parameters of lymphoma activity at FDG-PET/CT (SUV max $_{\text {, }}$ Deauville score). According to the Lugano criteria, a Deauville score $>3$ was defined as active lymphoma [11].

\section{Imaging Technique}

\section{SDCT}

All contrast-enhanced CT acquisitions were performed using a SDCT enabling spectral post-processing for material decomposition including calculation of iodine maps (IQon Elite Spectral CT, Philips Healthcare). Either one of the following $C T$ protocols was performed at the discretion of the radiologist in charge: (1) chest, abdomen, and pelvis in portal venous phase (protocol 1); (2) abdomen in arterial phase; chest, abdomen, and pelvis in portal venous phase (protocol 2).

Contrast medium with an iodine concentration of $350 \mathrm{mg} / \mathrm{mL}$ (iohexol, Accupaque 350, GE Healthcare) was administered via power injector with an injection rate of $3 \mathrm{ml} / \mathrm{s}$. The standard administered volume was $95 \mathrm{ml}$ for protocol 1 and $100 \mathrm{ml}$ for protocol 2 . The contrast medium volume could be adapted to the patient's constitution at the discretion of the radiologist in charge. The portal venous phase was acquired $60 \mathrm{~s}$ after completion of contrast medium injection. Conventional polychromatic images with a medium soft tissue kernel and iodine maps were reconstructed with a slice thickness of $3 \mathrm{~mm}$ and a reconstruction increment of $1.5 \mathrm{~mm}$ in transverse orientation.

\section{FDG-PET/CT}

FDG-PET/CT was performed after fasting for at least 6 hours. $4 \mathrm{MBq} / \mathrm{kg}$ body weight of FDG were administered intravenously about 60 min prior to the examination. All FDG-PET/CT acquisitions were performed using a Biograph mCT Flow scanner (Siemens Medical Solution). PET was acquired in $3 \mathrm{D}$ mode (matrix $200 \times 200$ ) using FlowMotion (Siemens). The emission data were corrected for randoms, scatter, and decay. Reconstruction was performed with an ordered subset expectation maximization (OSEM) algorithm with 2 iterations/21 subsets and Gauss-filtered to a transaxial resolution of $5 \mathrm{~mm}$ at full-width at half-maximum. Attenuation correction was performed using the non-enhanced low-dose CT data.

\section{Image analysis}

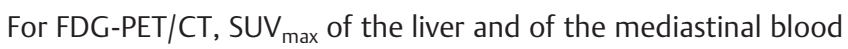
pool was determined. Lymphoma lesions were classified according to the Deauville score by a consensus panel consisting of a radiologist and a nuclear medicine physician based on their individual FDG-uptake. With reference to the Cheson criteria, a maximum number of 6 lymphoma lesions per patient were assessed [12]. If more than 6 lesions were available, the largest and most

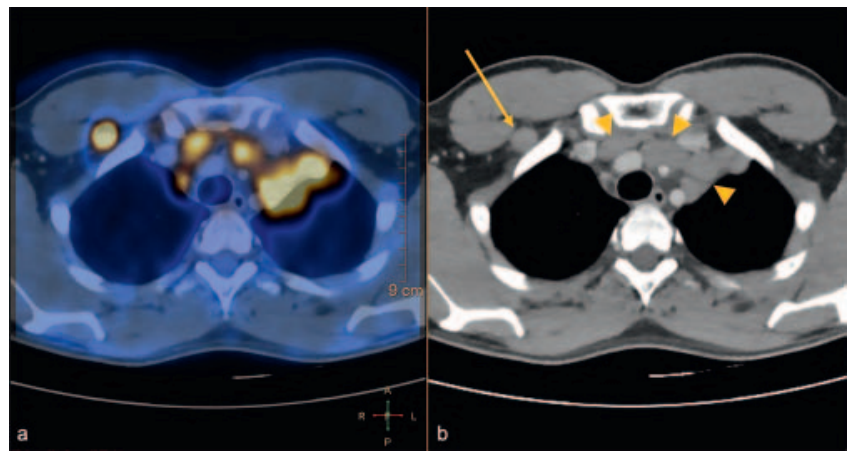

- Fig. 1 a Image example of automated co-registration of a PET acquisition with corresponding portal venous phase $\mathrm{CT}$ acquisition showing increased uptake in lymph nodes of the right infraclavicular region and mediastinum. b Original CT scan as reference for disease site (arrows).

- Abb. 1 a Bildbeispiel einer automatisierten Ko-Registrierung von PET-Akquisition und korrespondierendem portal-venösem CT. Es zeigen sich fokale Mehrspeicherungen in Lymphknoten infraklavikulär rechts sowie mediastinal. b Der originäre CT-Scan dient als Referenz für die Tumorlokalisation (Pfeile).

well-defined lesions were chosen for measurement. The Deauville score of each lesion and the maximum Deauville score of each patient was recorded. Deauville scores 4 and 5 were combined to form Deauville score $4 / 5$, because no objective rules for differentiation between both are available and the assignment of each score is merely based on subjective impression of FDG-uptake. PET acquisitions and portal venous phase CT acquisitions were automatically co-registered using dedicated software designed for aligning series of different modalities to improve anatomic correlation of lymphoma lesions (IntelliSpace Portal Version 11, Philips) ( $\triangleright$ Fig. 1).

For SDCT, AV and aIC of lymphoma lesions were recorded on conventional polychromatic images used for PET co-registration and iodine maps, respectively, using regions of interest (ROI) of identical size and location (IntelliSpace Portal Version 11, Philips). All measurements were conducted on images in the portal venous phase. All included lymphoma lesions exceeded a cranio-caudal diameter of $10 \mathrm{~mm}$ to allow for proper ROI placement and to reduce the risk of partial volume averaging artifacts as suggested by Patel et al. [13]. ROls were drawn manually in a circular fashion and care was taken to encompass the lesion portion with the most uptake in accordance with FDG-PET/CT.

Additional ROls were placed to calculate relative iodine concentrations normalized to the contrast enhancement of the inferior vena cava $\left(n \mid C_{v}\right)$, the abdominal aorta at the level of the celiac trunk $\left(n I C_{a}\right)$, and the lumbar muscle $\left(n I C_{m}\right)$ according to the following formula:

nIC lymphoma lesion = (alC lymphoma lesion $) /($ alC reference $)$

\section{Statistical analysis}

Deauville score subgroups were analyzed for differences in SDCT parameters using Kruskal-Wallis tests with Bonferroni post-hoc analysis. Spearman's correlation was used to determine the rela- 


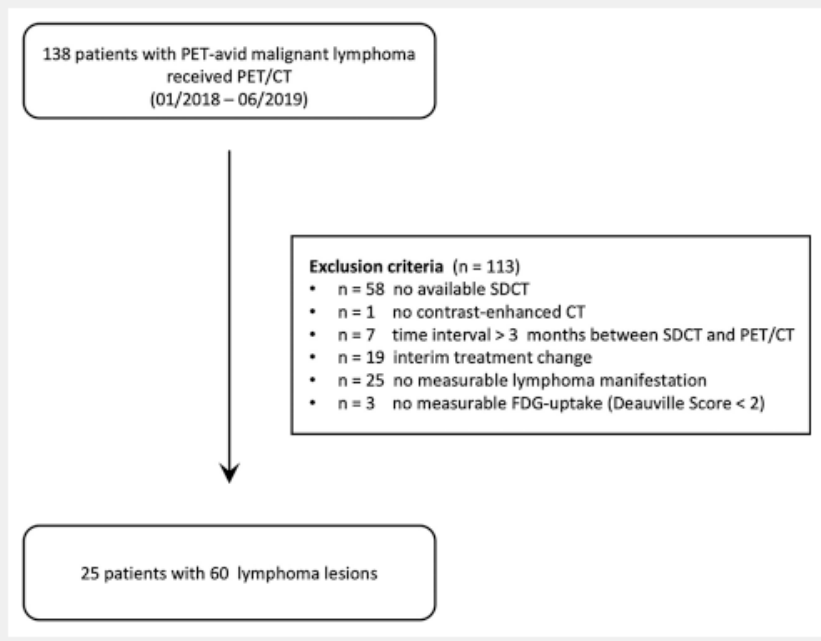

- Fig. 2 Outline of the patient selection process.

- Abb.2 Zusammenfassung der Patientenrekrutierung.

tionship between SUV $\mathrm{max}_{\text {ax }}$ and SDCT parameters. The sensitivity and specificity of SDCT parameters for the detection of active lymphoma (Deauville Score $>3$ ) were computed using a receiver operating characteristic (ROC) analysis. Optimal threshold values were estimated by maximizing the Youden's J statistic. The diagnostic accuracy of the threshold values was calculated. Statistical analysis was performed using SPSS Statistics (version 26, IBM). Statistical significance was assumed for $\mathrm{p}<0.05$.

\section{Results}

\section{Patient characteristics}

25 patients met the inclusion criteria (13 male; age: $41.6 \pm$ 16.1 years) ( $\triangleright$ Fig. 2). 9 patients had classical Hodgkin lymphoma, 8 patients had diffuse large B-cell lymphoma, and 5 patients had primary mediastinal B-cell lymphoma. One patient each had Burkitt-lymphoma, aggressive B-cell non-Hodgkin lymphoma, and T-lymphoblastic lymphoma ( $\triangleright$ Table 1). SDCT and FDG-PET/ $\mathrm{CT}$ were performed for primary staging in 3 patients, for treatment response evaluation in 20 patients, and for post-treatment follow-up in 2 patients. The overall median time interval between SDCT and FDG-PET/CT was 21.0 days (range: 7-87 days). In detail, the median time interval was 21.0 days (range: 14-33 days) for primary staging, 20.5 days (range: 7-87 days) for treatment response evaluation, and 31.0 days (range: 28-34 days) for posttreatment follow-up imaging. In 22 patients CT protocol 1 and in 3 patients CT protocol 2 was selected. The mean contrast medium volume was $90.4 \pm 8.4 \mathrm{ml}$ for protocol 1 and $78.6 \pm 7.8 \mathrm{ml}$ for protocol 2.

In the 25 patients, 60 lymphoma lesions were applicable for evaluation. Both nodal and extranodal lymphoma manifestations were included. The latter comprised splenic and hepatic manifestations as well as a lesion in the female pelvis. Extranodal manifestations accounted for $10 \%$ of all lymphoma lesions. Regarding
- Table 1 Lymphoma subtypes in order of frequency.

D Tab. 1 Lymphom-Subtypen sortiert nach Häufigkeit.

\begin{tabular}{|l|l|}
\hline Frequency & Subtype \\
\hline $36 \%$ & classical Hodgkin lymphoma \\
\hline $32 \%$ & diffuse large B-cell lymphoma \\
\hline $20 \%$ & primary mediastinal B-cell lymphoma \\
\hline $4 \%$ & Burkitt lymphoma \\
\hline $4 \%$ & aggressive B-cell non-Hodgkin lymphoma \\
\hline $4 \%$ & T-lymphoblastic lymphoma \\
\hline
\end{tabular}

- Table 2 Number of patients and lymphoma lesions per 5-PS.

- Tab.2 Anzahl Patienten und Lymphomläsionen gemäß DeauvilleScore.

\begin{tabular}{|l|l|l|}
\hline Deauville Score & \# Patients & \# Lesions \\
\hline 2 & 8 & 13 \\
\hline 3 & 10 & 16 \\
\hline $4 / 5$ & 10 & 31 \\
\hline
\end{tabular}

nodal lesions, 34 lesions were located in the chest area and 10 lesions each in the abdomen and pelvis area. The median for lesions per patient was 2 (range: 1-6). The number of lymphoma lesions per Deauville score is given in $\mathbf{T a b l e ~} 2$. Active lymphoma (Deauville score $>3$ ) was diagnosed in 10 patients and 31 lymphoma lesions ( $\triangleright$ Table 2 ).

\section{SDCT parameters per Deauville score}

SDCT parameter values per Deauville score are listed in $>$ Table 3. In general, higher values were found for higher Deauville scores. There were significant differences between Deauville score subgroups for aIC, $\mathrm{nIC}_{\mathrm{v}}, \mathrm{nIC}_{\mathrm{a}}$ and $\mathrm{AV}(\mathrm{p}<0.001$ each, KruskalWallis $\mathrm{H}$ test). Compared with Deauville score 4/5 (Bonferroni post hoc tests):

- alC was significantly lower for both Deauville scores 2 $(p<0.001)$ and $3(p=0.006)$.

- $\mathrm{nIC}_{\mathrm{v}}$ was significantly lower for both Deauville scores 2 $(p<0.001)$ and $3(p=0.004)$.

- $\mathrm{nIC}_{\mathrm{a}}$ was significantly lower for both Deauville scores 2 $(p<0.001)$ and $3(p=0.006)$.

- AV was significantly lower for both Deauville scores 2 $(p<0.001)$ and $3(p=0.027)$.

No significant differences were observed between Deauville scores 2 and 3. Effect sizes were large for pairwise comparison of Deauville scores 2 and $4 / 5$ for all parameters ( $r \geq 0.60)$. Effect sizes were medium for pairwise comparison of Deauville scores 3 and 
- Table 3 SDCT parameters and SUV max per Deauville score.

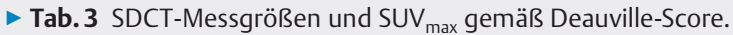

\begin{tabular}{|c|c|c|c|c|c|c|}
\hline Deauville Score & alC [mg/ml] & $\mathrm{nIC}_{\mathrm{v}}$ & $\mathrm{nIC}_{\mathrm{a}}$ & $n I C_{m}$ & $\mathrm{AV}[\mathrm{HU}]$ & SUV $_{\text {max }}$ \\
\hline 2 & $0.52 \pm 0.59$ & $0.16 \pm 0.20$ & $0.13 \pm 0.15$ & $4.32 \pm 4.73$ & $39.04 \pm 23.81$ & $1.77 \pm 0.32$ \\
\hline 3 & $0.71 \pm 0.52$ & $0.22 \pm 0.15$ & $0.19 \pm 0.14$ & $4.51 \pm 7.66$ & $53.38 \pm 18.39$ & $2.54 \pm 0.46$ \\
\hline $4 / 5$ & $1.25 \pm 0.50$ & $0.43 \pm 0.19$ & $0.35 \pm 0.14$ & $4.20 \pm 3.62$ & $69.86 \pm 17.49$ & $15.72 \pm 13.18$ \\
\hline
\end{tabular}

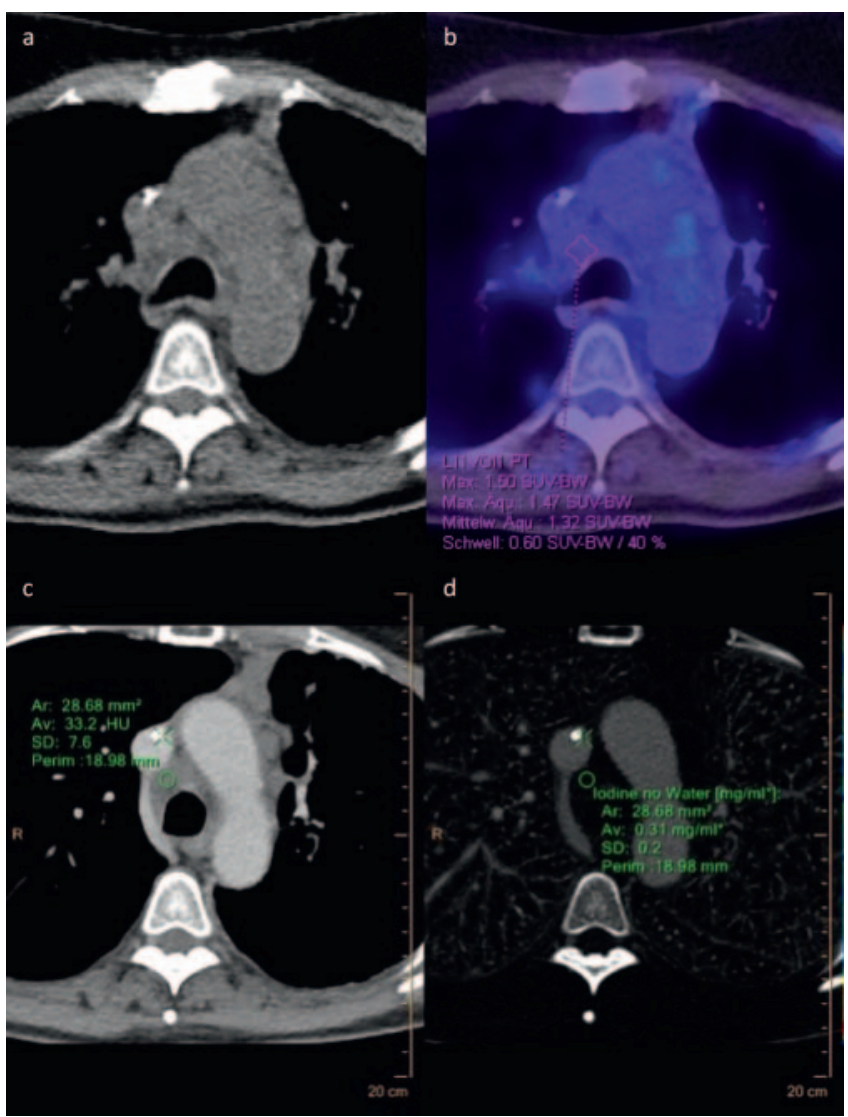

- Fig. 3 a non-contrast CT of PET/CT b PET scan c conventional polychromatic image in portal venous phase and $\mathbf{d}$ iodine map showing a mediastinal Deauville score 2 lymph node in position $4 R$.

- Abb. 3 a native PET/CT b PET-Scan c konventionell polychromatische Aufnahme in portalvenöser Phase $\mathbf{d}$ Jodkarte einer Deauville 2-Läsion mediastinal in Position 4R.

4/5 ( $r \geq 0.38)$. Fig. 3-5 show examples of inactive and active lymphoma lesions according to the Deauville score.

\section{Correlation between SDCT parameters and SUV $\max$}

There were significant linear correlations between SDCT para-

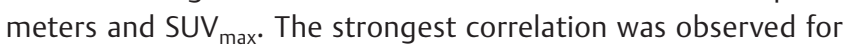
$\mathrm{nIC}_{\mathrm{v}}$ with $\rho=0.71(\mathrm{p}<0.001)$ and $\mathrm{nIC}_{\mathrm{a}}$ with $\rho=0.67(\mathrm{p}<0.001)$. For aIC, $\mathrm{nIC}_{\mathrm{m}}$ and AV Spearman's $\rho$ were 0.64 ( $\left.\mathrm{p}<0.001\right), 0.26$ $(p=0.045)$, and $0.60(p<0.001)$, respectively.

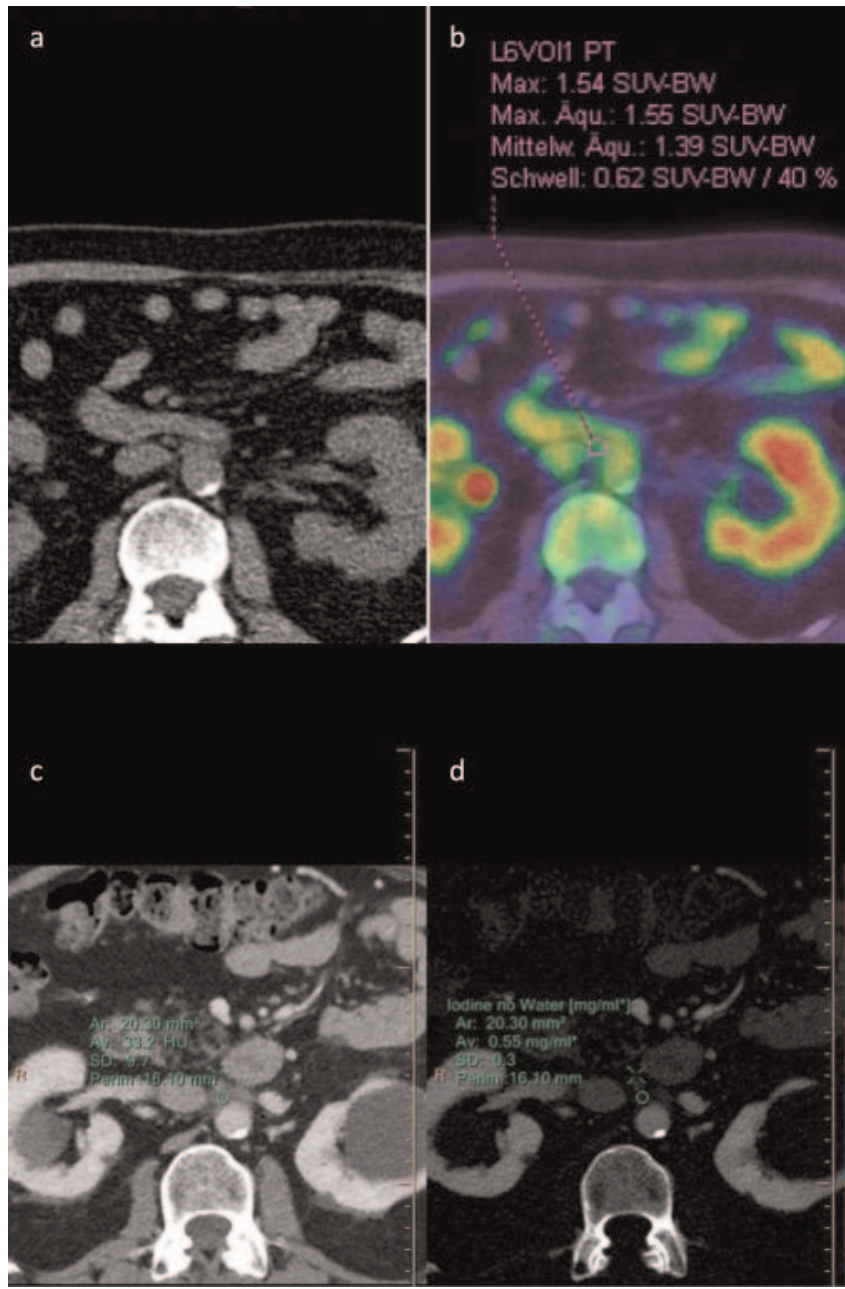

- Fig. 4 a non-contrast CT of PET/CT b PET scan c conventional polychromatic image in portal venous phase and $\mathbf{d}$ iodine map showing a paraaortal Deauville score 3 lymph node.

- Abb. 4 a native PET/CT b PET-Scan c konventionell polychromatische Aufnahme in portalvenöser Phase $\mathbf{d}$ Jodkarte einer Deauville 3-Läsion paraaortal.

\section{Diagnostic performance of SDCT parameters}

In a per-lesion analysis, the area under the ROC curve (AUROC) for the detection of active lymphoma was highest for $\mathrm{nIC}_{\mathrm{v}}(0.866)$. At a threshold of 0.20 , the sensitivity, specificity, and accuracy were 


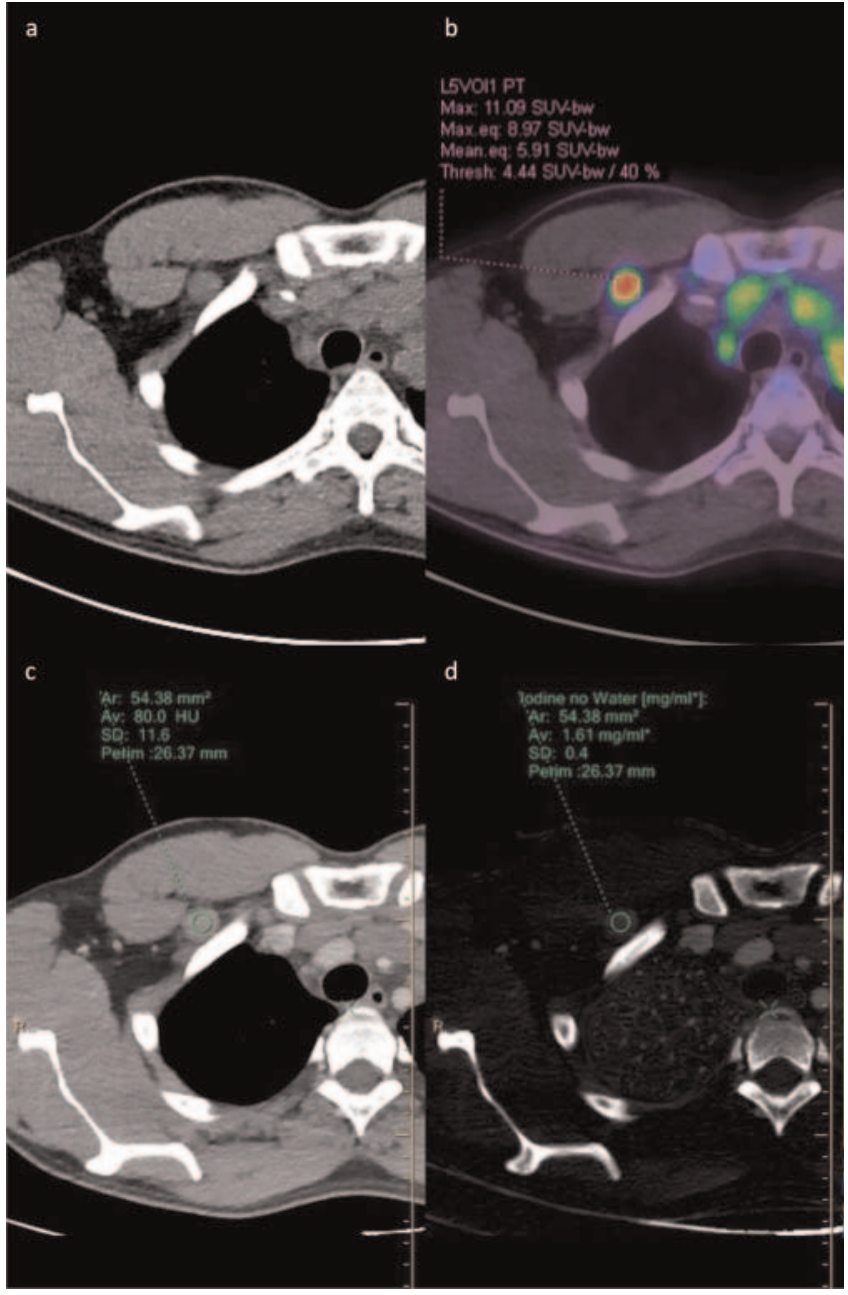

- Fig. 5 a non-contrast CT of PET/CT b PET scan c conventional polychromatic image in portal venous phase and $\mathbf{d}$ iodine map showing a Deauville score 4/5 lymph node of the right infraclavicular region.

- Abb. 5 a native PET/CT b PET-Scan c konventionell polychromatische Aufnahme in portalvenöser Phase d Jodkarte einer Deauville 4/5-Läsion rechts infraklavikulär.

$87 \%, 75 \%$, and $80 \%$, respectively. In descending order, the AUROC for $\mathrm{nIC}_{\mathrm{a}}$, aIC, $\mathrm{AV}$, and $\mathrm{nIC}_{\mathrm{m}}$ were $0.859,0.853,0.834$, and 0.609 , respectively. The sensitivity, specificity, and accuracy of all SDCT parameters are given in $>$ Table 4.

\section{Discussion}

We found significant correlations in lymphoma manifestations between SUV max $_{\text {and }} \mathrm{AV}$, alC and $\mathrm{nIC}$, respectively. The strongest correlation was found for $\mathrm{nIC}_{\mathrm{v}}$. Regarding ROC analyses, the overall performance levels of $\mathrm{AV}$, alC, and nIC were considerably high. The AUROC was highest for $n I C_{v}$ followed by $n I C_{a}$, suggesting that normalization of the iodine concentration to a reference tissue improves diagnostic accuracy.
Pairwise comparison of Deauville subgroups revealed significant differences between both Deauville scores 2 and 4/5, as well as between 3 and 4/5. However, no significant differences were found between Deauville scores 2 and 3. Deauville score 3 likely represents complete metabolic response in patients undergoing standard treatment [14] and was therefore considered inactive lymphoma. This might be the reason that differences between Deauville scores 2 and 3 were not as great as compared to Deauville score 4/5 since the latter represents active lymphoma.

Based on the hypothesis that malignant infiltration of lymph nodes also causes an increase in $\mathrm{CT}$ density by dissolving the fatty hilus [15], the performance of conventional HU values was also tested. In this study, CT attenuation values performed almost on par with absolute iodine concentration. This suggests that CT density by itself might serve as a valuable surrogate parameter. Conclusive with this finding, Giesel et al. found higher CT density values in nonenhanced malignant vs. benign lymph nodes in a trial analyzing 1022 lymph nodes in different solid tumors [16]. Lee et al. also observed that lymph node density combined with SUV max $_{\text {increased }}$ sensitivity for mediastinal metastases in lung cancer patients if FDG-uptake was only mild [17]. Flechsig et al. further found that CT density measurements aided with the characterization of target lymph nodes in lung cancer [15] and lymphoma patients [18].

However, when diagnosing malignant tumors on imaging, we look for tumor-associated neovascularization since it represents one of the hallmarks of cancer biology [19]. In contrast-enhanced SDCT, tissue enhancement can be visualized on iodine maps. SDCT further allows for direct quantification of iodine uptake without the need of multiphase CT [10], which Chandarana et al. showed to be accurate in a phantom study [20]. Several studies suggested that the use of contrast-enhanced SDCT improves correct characterization of a lesion [10, 21-23]. Most recently, two studies found dual-energy CT parameters including iodine concentration to be useful for the identification of pulmonary nodules regarding primary lung cancer and pulmonary metastasis in thyroid cancer $[24,25]$. Moreover, iodine concentration was found to be a useful marker for vascularization in treatment response assessment in lung cancer $[8,26]$, renal cell cancer [27], hepatocellular carcinoma [9, 28], and gastrointestinal stroma tumor [29]. In a recent study on the local recurrence of pancreatic ductal adenocarcinoma, iodine concentration was also identified as a potential tool for differentiating non-specific post-operative tissue proliferation [30]. These findings coincide with our results regarding the role of iodine concentration as a potential biomarker for tumor activity. Another aspect to consider is that FDG-uptake in tissues is not only dependent on tumorassociated neovascularization, but also the expression of glucose transporters, hexokinase activity on a cellular level, and non-neoplastic metabolic activity. The latter also applies for iodine uptake. Thus, despite differing uptake mechanisms for FDG and iodine, we assumed that there are sufficient similarities for comparison regarding our study.

There were noticeable differences in reported thresholds in the literature regarding lesion vascularization and malignancy. In our study we found a threshold of $0.96 \mathrm{mg}$ iodine $/ \mathrm{ml}$ for the detection of active lymphoma. For instance, Li et al. reported a far lower threshold to distinguish metastatic from non-metastatic lymph 
- Table 4 Diagnostic performance of SDCT parameters for the detection of active lymphoma.

- Tab.4 Diagnostische Vorhersagekraft der SDCT-Messgrößen zur Detektion von Lymphomaktivität.

\begin{tabular}{|l|l|l|l|l|l|}
\hline & alC & nIC & nIC & nIC & AV \\
\hline AUROC & 0.853 & 0.866 & 0.859 & 0.609 & 0.834 \\
\hline Threshold & $0.96[\mathrm{mg} / \mathrm{ml}]$ & 0.20 & 0.28 & 1.45 & $52.6[\mathrm{HU}]$ \\
\hline Sensitivity & $74 \%$ & $87 \%$ & $74 \%$ & $94 \%$ & $90 \%$ \\
\hline Specificity & $86 \%$ & $75 \%$ & $89 \%$ & $36 \%$ & $68 \%$ \\
\hline Accuracy & $78 \%$ & $80 \%$ & $80 \%$ & $65 \%$ & $78 \%$ \\
\hline
\end{tabular}

nodes in lung cancer [8]. However, to our knowledge there have been no reported thresholds in iodine concentrations regarding lymphoma patients. Apart from differences in tumor entities, Patel et al. suggested other reasons that could account for differences in threshold reports, such as patient populations and differing scanning protocols [13].

Since contrast uptake may vary interindividually due to factors such as patient constitution, bolus timing, and cardiac output [31], normalization of iodine concentration was introduced to reduce variability. Similar to our observations, Patel et. Al found that normalizing iodine concentration to the abdominal aorta improves the separation of vascular and nonvascular renal lesions [13]. In this study, normalization to the abdominal aorta, inferior vena cava, and lumbar muscles was tested. The latter performed poorly and yielded no significant results. On the other hand, normalization to the large abdominal vessels showed substantial results and $\mathrm{nIC}_{\mathrm{v}}$ outperformed $\mathrm{nIC}_{\mathrm{a}}$ slightly but not significantly.

There were several limitations of this study, mainly due to its retrospective design. First, with 60 lymphoma lesions in total, the overall sample size of our study was rather small. As mentioned before, we refrained from including more than 6 lesions per patient in reference to the Cheson criteria. On the one hand, this limited the maximum impact of a single patient on the results. On the other hand, this process might have led to a selection bias since lesion preselection took place manually. Second, the investigated cohort demonstrated heterogeneity in regard to lymphoma subtype, distribution of Deauville score, and treatment interval. There were variable delays regarding the time period between SDCT and FDG-PET/CT lasting up to 3 months in some cases. Thus, even though both examinations were performed within the same treatment interval, progression of disease in the interim may have occurred and affected accurate correlation.

Third, a single operator executed ROI placement for all lesions which might have led to an observation bias. Moreover, a second reader could have been introduced to test interobserver variability. The ROI placement was conducted manually and did not necessarily encompass the entirety of each lesion, accounting for another potential source of inaccuracy. Lastly, the use of volumetric measurements instead of a two-dimensional analysis may improve the representativeness of iodine uptake measurement. In order to achieve a more robust, complete acquisition of iodine distribution and to examine the degree of heterogeneity of iodine distribution in tissues, volumetric measurements should be part of further studies.

In the majority of cases imaging was conducted for treatment response evaluation, thus initial acquisition parameters for reference were not available. An additional study including baseline and follow-up SDCT for lymphoma patients would be of interest to observe changes in iodine concentration over the treatment process. Simultaneously, if a larger cohort was available, iodine concentration in naïve and treated lesions should be investigated separately regarding their correlation with SUV $\mathrm{max}_{\max }$ to observe the influence of treatment effects such as necrosis. Furthermore, if baseline SDCT is available, lymphoma manifestations should be compared with benign lymph nodes to examine differences in iodine uptake.

\section{Conclusion}

In conclusion, in patients with malignant lymphoma, iodine concentration may represent an alternative imaging biomarker to FDG-avidity. Concerning correlation to FDG-PET/CT, normalization of iodine concentration to reference tissues such as the inferior vena cava improves the diagnostic performance of iodine concentration.

\section{CLINICAL RELEVANCE}

- In patients with FDG-avid lymphoma, PET/CT is usually used for response assessment.

- Spectral detector CT enables material decomposition and measurement of iodine concentration, thereby providing an alternative method to investigate tumor activity.

- In patients with malignant lymphoma, iodine concentration may serve as a surrogate parameter for disease activity.

\section{Conflict of Interest}

The authors of this manuscript declare relationships with the following companies:

K. Gehling: None

T. Mokry: None

T. D. Do: Speakers' bureau Philips Healthcare 
F. L. Giesel: None

S. Dietrich: None

U. Haberkorn: None

H.-U. Kauczor: Research grant and speakers' bureau Philips Healthcare

T. F. Weber: None

\section{References}

[1] El-Galaly TC, Gormsen LC, Hutchings M. PET/CT for Staging; Past, Present, and Future. Semin Nucl Med 2018; 48: 4-16. doi:10.1053/ j.semnuclmed.2017.09.001

[2] Barrington SF, Mikhaeel NG, Kostakoglu L et al. Role of imaging in the staging and response assessment of lymphoma: consensus of the International Conference on Malignant Lymphomas Imaging Working Group. J Clin Oncol 2014; 32: 3048-3058. doi:10.1200/JCO.2013.53.5229

[3] Cheson BD, Pfistner B, Juweid ME et al. Revised response criteria for malignant lymphoma. J Clin Oncol 2007; 25: 579-586. doi:10.1200/ JCO.2006.09.2403

[4] Follows GA, Ardeshna KM, Barrington SF et al. Guidelines for the first line management of classical Hodgkin lymphoma. Br J Haematol 2014; 166: 34-49. doi:10.1111/bjh.12878

[5] Barrington SF, Mikhaeel NG. When should FDG-PET be used in the modern management of lymphoma? Br J Haematol 2014; 164: 315-328. doi:10.1111/bjh.12601

[6] Rutten A, Prokop M. Contrast agents in X-ray computed tomography and its applications in oncology. Anticancer Agents Med Chem 2007; 7: 307-316. doi:10.2174/187152007780618162

[7] Rassouli N, Etesami M, Dhanantwari A et al. Detector-based spectral CT with a novel dual-layer technology: principles and applications. Insights Imaging 2017; 8: 589-598. doi:10.1007/s13244-017-0571-4

[8] Li Q, Li X, Li XY et al. Spectral CT in Lung Cancer: Usefulness of lodine Concentration for Evaluation of Tumor Angiogenesis and Prognosis. Am J Roentgenol 2020; 215: 595-602. doi:10.2214/ajr.19.22688

[9] Luo N, Li W, Xie J et al. Preoperative normalized iodine concentration derived from spectral CT is correlated with early recurrence of hepatocellular carcinoma after curative resection. Eur Radiol 2020. doi:10.1007/s00330-020-07330-6

[10] Simons D, Kachelriess M, Schlemmer HP. Recent developments of dualenergy CT in oncology. Eur Radiol 2014; 24: 930-939. doi:10.1007| s00330-013-3087-4

[11] Cheson BD, Fisher RI, Barrington SF et al. Recommendations for initial evaluation, staging, and response assessment of Hodgkin and nonHodgkin lymphoma: the Lugano classification. J Clin Oncol 2014; 32: 3059-3068. doi:10.1200/JCO.2013.54.8800

[12] Cheson BD, Horning SJ, Coiffier B et al. Report of an international workshop to standardize response criteria for non-Hodgkin's lymphomas. $\mathrm{NCl}$ Sponsored International Working Group. J Clin Oncol 1999; 17: 1244. doi:10.1200/JCO.1999.17.4.1244

[13] Patel BN, Vernuccio F, Meyer M et al. Dual-Energy CT Material Density lodine Quantification for Distinguishing Vascular From Nonvascular Renal Lesions: Normalization Reduces Intermanufacturer Threshold Variability. Am J Roentgenol 2019; 212: 366-376. doi:10.2214/Am J Roentgenol.18.20115

[14] Barrington SF, Kirkwood AA, Franceschetto A et al. PET-CT for staging and early response: results from the Response-Adapted Therapy in Advanced Hodgkin Lymphoma study. Blood 2016; 127: 1531-1538. doi:10.1182/blood-2015-11-679407

[15] Flechsig P, Kratochwil C, Schwartz LH et al. Quantitative volumetric CThistogram analysis in N-staging of 18F-FDG-equivocal patients with lung cancer. J Nucl Med 2014; 55: 559-564. doi:10.2967/jnumed.113.128504
[16] Giesel FL, Schneider F, Kratochwil C et al. Correlation Between SUVmax and CT Radiomic Analysis Using Lymph Node Density in PET/CT-Based Lymph Node Staging. J Nucl Med 2017; 58: 282-287. doi:10.2967| jnumed.116.179648

[17] Lee JW, Kim EY, Kim DJ et al. The diagnostic ability of (18)F-FDG PET/CT for mediastinal lymph node staging using (18)F-FDG uptake and volumetric CT histogram analysis in non-small cell lung cancer. Eur Radiol 2016; 26: 4515-4523. doi:10.1007/s00330-016-4292-8

[18] Flechsig P, Walker C, Kratochwil C et al. Role of CT Density in PET/CTBased Assessment of Lymphoma. Mol Imaging Biol 2018; 20: 641-649. doi:10.1007/s11307-017-1155-x

[19] Hanahan D, Weinberg RA. Hallmarks of cancer: the next generation. Cell 2011; 144: 646-674. doi:10.1016/j.cell.2011.02.013

[20] Chandarana H, Megibow A], Cohen BA et al. lodine quantification with dual-energy $C T$ : phantom study and preliminary experience with renal masses. Am J Roentgenol 2011; 196: W693-700. doi:10.2214/Am J Roentgenol.10.5541

[21] Andersen MB, Ebbesen D, Thygesen J et al. Impact of spectral body imaging in patients suspected for occult cancer: a prospective study of 503 patients. Eur Radiol 2020; 30: 5539-5550. doi:10.1007/s00330020-06878-7

[22] Kessner R, Große Hokamp N, Ciancibello L et al. Renal cystic lesions characterization using spectral detector CT (SDCT): Added value of spectral results. Br J Radiol 2019; 92: 20180915. doi:10.1259/ bjr.20180915

[23] Ascenti G, Mileto A, Krauss B et al. Distinguishing enhancing from nonenhancing renal masses with dual-source dual-energy $C T$ : iodine quantification versus standard enhancement measurements. Eur Radiol 2013; 23: 2288-2295. doi:10.1007/s00330-013-2811-4

[24] Ha T, Kim W, Cha J et al. Differentiating pulmonary metastasis from benign lung nodules in thyroid cancer patients using dual-energy CT parameters. Eur Radiol 2021. doi:10.1007/s00330-021-08278-x

[25] Wen Q, Yue Y, Shang J et al. The application of dual-layer spectral detector computed tomography in solitary pulmonary nodule identification. Quant Imaging Med Surg 2021; 11: 521-532. doi:10.21037| qims-20-2

[26] Baxa J, Matouskova T, Krakorova G et al. Dual-Phase Dual-Energy CT in Patients Treated with Erlotinib for Advanced Non-Small Cell Lung Cancer: Possible Benefits of lodine Quantification in Response Assessment. Eur Radiol 2016; 26: 2828-2836. doi:10.1007/s00330-015-4092-6

[27] Hellbach K, Sterzik A, Sommer W et al. Dual energy CT allows for improved characterization of response to antiangiogenic treatment in patients with metastatic renal cell cancer. Eur Radiol 2017; 27: 2532-2537. doi:10.1007/s00330-016-4597-7

[28] Dai X, Schlemmer HP, Schmidt B et al. Quantitative therapy response assessment by volumetric iodine-uptake measurement: initial experience in patients with advanced hepatocellular carcinoma treated with sorafenib. Eur J Radiol 2013; 82: 327-334. doi:10.1016/j.ejrad.2012.11.013

[29] Apfaltrer P, Meyer M, Meier C et al. Contrast-enhanced dual-energy CT of gastrointestinal stromal tumors: is iodine-related attenuation a potential indicator of tumor response? Invest Radiol 2012; 47: 65-70. doi:10.1097/RLI.0b013e31823003d2

[30] Mathy RM, Fritz F, Mayer P et al. lodine concentration and tissue attenuation in dual-energy contrast-enhanced $\mathrm{CT}$ as a potential quantitative parameter in early detection of local pancreatic carcinoma recurrence after surgical resection. Eur J Radiol 2021; 143: 109944. doi:10.1016/ j.ejrad.2021.109944

[31] Platt JF, Reige KA, Ellis JH. Aortic enhancement during abdominal CT angiography: correlation with test injections, flow rates, and patient demographics. Am J Roentgenol 1999; 172: 53-56. doi:10.2214/ ajr.172.1.9888738 